\section{Concept of persons}

Sir: I enjoyed Dr Oyebode's article on the concept of persons in animals, humans and Martians (Psychiatric Bulletin, 1995, 19, 212-216). I agree with him that trying to operationalise fixed attributes defining personhood in others is problematic and that an "imaginative sense of kinship" better described what is really a particular kind of relationship, containing identification and empathy. There are links here to everyday experience.

Within child psychiatry, one watches regularly how scapegoated children loose their 'humanness'. Attributions to them take on just the kind of nonhuman quality described by Oyebode; the child is 'an alien', weird', 'like an animal', 'like a Martian', say the parents. They see the child's behaviour as having non-human roots; empathy is lost.

Contrartwise, non-humans can legitimately be elevated to the status of 'persons' within a particular relationship. One thinks of people with treasured pets or the blind with their guide dogs. Such animals may truly be treated psychologically as human (for instance by real grieving at their loss or the wish to make a 'human' type burial).

If what is included as 'human' depends essentially on a relationship, then this is by its nature subjective and does not offer any $a$ pritori rules about general social rights. Presumably these latter derive from emerging social consensus over time. However slow these may be to develop. I propose that this is safer than the alternative route described by Oyebode - abstracted definitions becoming extended into general 'rights' outside any relational context.

For example Dr Oyebode points to this century's discovery of personhood in the handicapped'. Is not this the end result of initial relationships dertved from the personal imaginative 'discovery' of particular disabled people as persons, leading through research and advocacy to gradual social consensus? Subsequently then this can be codified in terms of 'rights'.

Gaining such consensus will probably always involve a struggle against resistance because new inclusions into kinship represent a profound shift in group perception. We see the same in clinical treatment as a family struggles back into an emphatic relatedness with their child, restoring that child's 'humanness' as they do so.

\section{JONATHAN GREEN}

Department of Child and Family Psychiatry.

Booth Hall Children's Hospital,

Charlestown Road, Blackley, Manchester M9 2AA

Sir: Dr Green and I are agreed, I think, that the attempts by some philosophers to distinguish the class 'person' from the class 'human being' are problematic. In my view, the main problem is that they are liable to lead to conclusions which one finds instinctively repugnant, as for example when Singer (1993) says "we are now saying that many non-human animals have the same kind of right to life that normal humans have; and we are saying that there are some human beings - newborn infants and those with severe mental retardation - who do not have this kind of right to life". Singer re-emphasises this point by saying "we have to recognise that there are still some humans - those with irreparable severe mental retardation - who are not persons and who do not have the same right to life that persons, including non-human persons have".

The purpose of my paper was to argue against philosophers like Singer by claiming that the notion human being has a significant place in moral thought and that our personhood (humanity) is not determined by possession of particular features such as consciousness, language, but rather by our imaginative capacity to see the other as like ourselves. Dr Green's point is to explain how 'our imaginative sense of kinship may be grounded in the nature of a particular kind of relationship containing identification and empathy. I would prefer to argue that our imaginative capacity (what some authors now call having a theory of mind) includes such processes as identification and empathy which allow us to enter into relationships with others. However, herein lies the problem with this approach; it seems arbitrary and lacking in intellectual rigour. It can be misconstrued as saying that a person is anyone or anything I imagine to be a person and that this privilege is conferred by me upon others or vice versa.

There are difficulties whichever position one takes but in my view the position least likely to introduce a new form of discrimination based upon intelligence or brain function rather than race or sex is that shared by Dr Green and $I$.

SINGER, P. (1993) Animals and the value of life. In Matters of Lfe and Death (ed. T. Regan), pp. 280-321. New York: McGraw-Hill.

FEMI OYebode

South Birmingham Mental Health NHS Trust, The Queen Elizabeth Psychiatric Hospital, Edgbaston, Birmingham B15 $29 Z$

\section{Oedipus Rex: enduring archetypal clasale}

I watched the portrayal of Oedipus Rex in a drama in a different culture many years ago. The interpretation by Oyebode \& Pourgourides (Psychiatric Bulletin, 1995, 19, 362-363) of Sophocle's 